\title{
Mechanisms of endocrine resistance in breast cancer: an overview of the proposed roles of noncoding RNA
}

\author{
Erin L Hayes ${ }^{1,2}$ and Joan S Lewis-Wambi ${ }^{1,2^{*}}$
}

\begin{abstract}
Endocrine therapies such as tamoxifen and aromatase inhibitors are the standard treatment options for estrogen receptor-positive breast cancer patients. However, resistance to these agents has become a major clinical obstacle. Potential mechanisms of resistance to endocrine therapies have been identified, often involving enhanced growth factor signaling and changes in the expression or action of the estrogen receptor, but few studies have addressed the role of noncoding RNA (ncRNA). Two important types of ncRNA include microRNA (miRNA) and long noncoding RNA (IncRNA). miRNAs are small RNA molecules that regulate gene expression via translational inhibition or degradation of mRNA transcripts, while IncRNAs are larger RNA molecules that have been shown to play a role in multiple cellular maintenance functions such as protein scaffolding, chromatin looping, and regulation of mRNA stability. Both miRNA and IncRNA have recently impacted the field of breast cancer research as important pieces in the mechanistic puzzle of the genes and pathways involved in breast cancer development and progression. This review serves as an overview of the roles of miRNA and IncRNA in breast cancer progression and the development of endocrine resistance. Ideally, future experiments in the field should include identification of ncRNAs that could be potential therapeutic targets in endocrine-resistant tumors, as well as ncRNA biomarkers that facilitate more tumor-specific treatment options for endocrine-resistant breast cancer patients.
\end{abstract}

\section{Introduction}

Breast cancer is the most commonly diagnosed cancer in the United States and is the second leading cause of cancer death. Approximately one out of every eight US women will develop invasive breast cancer over the course of her lifetime [1]. About $70 \%$ of all breast cancers express estrogen receptor (ER) alpha and belong to the molecular subtypes luminal A or luminal B $[1,2]$. While the exact etiology of breast cancer is not known, there is strong evidence that estrogen plays a critical role in the development and progression of the disease. $E R \alpha$-positive breast cancers rely on estrogen signaling for proliferation, and hence the most effective strategy to stop or slow the growth of these hormone-sensitive tumors is to block estrogen action in the tumor using endocrine therapy. Current endocrine therapies for

\footnotetext{
* Correspondence: jlewis-wambi@kumc.edu
'Department of Cancer Biology, University of Kansas Medical Center, 3901

* Correspondence: jlewis-wambi@kumc.edu Rainbow Blvd, Wahl Hall East 1031, Kansas City, KS 66160, USA

${ }^{2}$ Department of Physiology, University of Kansas Medical Center, Kansas City, KS 66160, USA
}

\section{Biomed Central}

(c) 2015 Hayes and Lewis-Wambi; licensee BioMed Central. This is an Open Access article distributed under the terms of the Creative Commons Attribution License (http://creativecommons.org/licenses/by/4.0), which permits unrestricted use, distribution, and reproduction in any medium, provided the original work is properly credited. The Creative Commons Public Domain Dedication waiver (http://creativecommons.org/publicdomain/zero/1.0/) applies to the data made available in this article, unless otherwise stated.

$\mathrm{ER} \alpha$ breast cancer include: tamoxifen, the selective ER modulator that antagonizes ER $\alpha$ function; fulvestrant, the pure anti-estrogen that degrades/downregulates ER $\alpha$; and aromatase inhibitors (AIs) (letrozole, anastrozole, and exemestane), which suppress estrogen production in peripheral tissues by blocking the aromatase enzyme. Unfortunately, the majority of patients treated with endocrine therapy eventually develop resistance, leading to disease progression and death. The mechanism by which resistance occurs is still not completely known and thus represents a major clinical problem. This review will offer information regarding the recently studied roles of noncoding RNAs (ncRNAs) in acquired endocrine resistance.

Estrogen mediates its biological effects by binding to ER $\alpha$ and ER $\beta$, which are members of the nuclear receptor superfamily of ligand-inducible transcription factors [3,4]. ER $\alpha$ is encoded by ESR1, a $300 \mathrm{~kb}$ gene located on chromosome 6, and has six functional domains, A to F, which include both ligand-binding and DNA-binding 
domains, as described by Kumar and coworkers [5]. It is also important to note that there are multiple sites of phosphorylation on ER $\alpha$. For instance, Ser118 phosphorylation by a mitogen-activated protein kinase (MAPK) leads to ligand-independent activation of ER $\alpha$ activity, and Ser167 phosphorylation by protein kinase $\mathrm{B}$ (Akt) can also lead to ligand-independent activation of $E R \alpha[6,7]$.

When estrogen binds ER $\alpha$, the receptor dimerizes and translocates to the nucleus where it binds estrogen response elements in the DNA, stimulating transcription of target genes involved in cell proliferation [8]. The estrogen-activated ER $\alpha$ is also able to bind other transcription factors, such as Ap-1 and Sp-1, independent of estrogen response elements, where it may recruit coactivators to stimulate transcription of additional growth and survival genes [9]. Much of the molecular signaling mediated by ER $\alpha$ involves the MAPK and phosphoinositide 3-kinase (PI3K) pathways, the primary facilitators of cell growth and proliferation [10].

\section{Endocrine therapies Estrogen receptor antagonists}

Targeting ER $\alpha$ using selective ER modulators and selective ER downregulators has been an effective treatment strategy for patients with ER $\alpha$-positive hormonedependent breast cancer. For the past few decades, the selective ER modulator tamoxifen has been the most widely used drug for the treatment of breast cancer, with success both as a long-term adjuvant therapy and as a preventative agent for women at increased risk for breast cancer [11,12]. Normally, estrogen-bound ER $\alpha$ is in a conformation that favors the recruitment of coactivators to promote transcription of target genes. However, when tamoxifen binds to the ligand-binding domain of ER $\alpha$ in mammary epithelium, it induces a conformation that recruits corepressors, which blocks estrogen from binding its receptor and prevents the proliferative action of ER $\alpha$ signaling [13]. In addition to tamoxifen, the use of selective ER downregulators, which act as pure anti-estrogens, has also been under investigation. Only one selective ER downregulator, fulvestrant, has thus far been approved for clinical use [14].

\section{Aromatase inhibitors}

While ER antagonists have played an important role in combating ER $\alpha$-positive breast cancers for the past few decades, another class of therapies has emerged - AIs. The aromatase enzyme (a cytochrome P450 hemecontaining protein) is required for the synthesis of estrogen via aromatization of androgens such as testosterone [15]. Circulating levels of estrogen decrease as a woman enters menopause, since there is no longer production of estrogen by the ovaries. Thus, the local synthesis of estrogen by breast adipose tissue plays a large role in the growth and survival of ER $\alpha$-positive breast tumors [16]. Inhibition of aromatase activity in these tumors is a rational treatment strategy to suppress estrogen production in peripheral tissues, thus inhibiting tumor growth.

Currently, there are three US Food and Drug Administration-approved oral AIs in clinical use for the treatment of postmenopausal women with hormone receptor-positive breast cancer. These AIs can be divided into two categories: steroidal AIs (exemestane) and nonsteroidal AIs (anastrozole, letrozole). There has been great interest in the development of AIs since it has been observed in clinical trials that they can be more tolerable than tamoxifen, and are usually more effective or equivalently effective in clinical response rate and median time to progression [17]. Indeed, the thirdgeneration AIs have all been shown to suppress circulating estrogen levels in postmenopausal breast cancer patients by more than $97 \%[18,19]$.

\section{Resistance to endocrine therapies Mechanisms of tamoxifen resistance}

Many of the key pathways involved in tamoxifen resistance involve growth factors, such as human epidermal growth factor receptor 2 (HER2) (Figure 1A). The growth of the tamoxifen-resistant cell model MCF-7/HER2-18 (HER2 overexpressing) is increased with treatment of tamoxifen, revealing a crosstalk between HER2 and ER $\alpha$ [20]. Likewise, early in vivo studies of breast tumors by Gottardis and Jordan revealed that, in the process of acquiring tamoxifen resistance, tumors may gain the ability to grow in a tamoxifen-stimulated manner [21]. There is strong evidence that the ability of tamoxifen to function as an agonist or an antagonist is dependent on whether it recruits coactivators or corepressors to the ER $\alpha$ transcription complex [22]. Perhaps the most studied coregulator of ER $\alpha$ is the amplified in breast cancer 1 (AIB1) protein. Increased expression of AIB1 correlates with tamoxifen resistance since AIB1 expression contributes to the agonistic activity of tamoxifen - especially in the presence of HER2 (Figure 1A) [23].

In addition to HER2 signaling, the growth factor receptors insulin-like growth factor receptor 1 and fibroblast growth factor receptor 1 can activate the MAPK and PI3K pathways, which have been shown to confer tamoxifen unresponsiveness [24,25]. Altered expression of ER $\alpha$ also contributes to the development of tamoxifen resistance. Since ER $\alpha$ is the target of tamoxifen treatment, lack of $\mathrm{ER} \alpha$ expression is known to result in resistance. Hypermethylation of $\mathrm{CpG}$ islands and histone deacetylase activity in the ESR1 promoter (Figure 1A) are similar to the absence of ER $\alpha$ because these can inactivate the gene so the cells express much less ER $\alpha$ [26]. 



Figure 1 Mechanisms of endocrine resistance in breast cancer cells. (A) Mechanisms of tamoxifen (TAM) resistance may involve the loss of estrogen receptor (ER) alpha expression, which can be achieved by methylation of CpG islands or histone deacetylase activity in the ESR1 promoter. Tamoxifen-resistant growth is also stimulated by the upregulation of growth factor signaling pathways (HER2, IGFR1, and FGFR1) and subsequent activation of the mitogen-activated protein kinase (MAPK) cascade or phosphoinositide 3-kinase (PI3K) pathway. Finally, tamoxifen has even been shown to stimulate the growth of breast cancer cells when bound to certain coactivators, such as AIB1, and this is especially true in HER2-expressing cells. (B) The mechanisms of aromatase inhibitor (Al) resistance share similarities with tamoxifen resistance, especially in terms of growth factor pathway upregulation. The enhanced activity of growth factors such as MAPK can result in estrogen-independent phosphorylation and activation of ERa. In addition to growth factor signaling, interferon response genes and anti-apoptotic proteins have also been shown to have increased expression in Al-resistant cells. AIB1, amplified in breast cancer 1; FGFR1, fibroblast growth factor receptor 1; HER2, human epidermal growth factor receptor 2; IGFR1, insulin-like growth factor receptor 1.

Resistance to tamoxifen can also arise from dysregulated metabolism of the drug. In the liver, cytochrome P450 enzymes CYP2D6 and CYP3A4 convert tamoxifen to its active metabolites 4-hydroxytamoxifen and endoxifen, which both have 30 -fold to 100-fold higher potency to inhibit estrogen-dependent proliferation than tamoxifen [27]. Polymorphisms in the cytochrome P450 proteins, especially CYP2D6, have been associated with poor metabolic activity, and are associated with worse clinical outcome after tamoxifen treatment $[28,29]$. In addition, it is also possible that altered cellular accumulation of tamoxifen and its metabolites - potentially through the induction of efflux transporters such as P- glycoprotein/multi-drug resistance protein 1 (MDR1) might influence a patient's response to tamoxifen [30]. Notably, P-glycoprotein expression has been associated with a shorter overall survival for tamoxifen-treated patients, but its use as a prognostic marker is still under investigation $[31,32]$.

\section{Mechanisms of aromatase inhibitor resistance}

There are several pathways implicated in the acquired AI-resistant phenotype. These include the MAPK [33], epidermal growth factor receptor [34], and PI3K pathways (Figure 1B) [35]. ER $\alpha$ has also been shown to play a role in AI resistance, in the form of a constitutively 
active ligand-independent mutant ER $\alpha$ [36], via different genome binding patterns [37], or simply by modified expression levels [38]. In fact, one study reveals that ligand-independent ER $\alpha$ activation is required for the development of an AI-resistant phenotype in the aromatase-overexpressing MCF-7aro cell line [39]. The phosphorylation of ER $\alpha$ by MAPK (Ser118) and Akt (Ser167) is often essential for the ligand-independent action of ER $\alpha$, as discussed previously (Figure 1B) $[6,7]$.

Since the mechanism by which AIs induce death of ER-positive breast cancer cells often involves apoptosis, a disturbance in the balance of pro-apoptotic and antiapoptotic genes could also play a role in resistance to AI treatment (Figure 1B) [40]. Indeed, this imbalance has been shown in an aromatase-expressing MCF-7 cell line with a mutant ER $\alpha$ gene (K303R) [41]. The K303R mutation was shown to cause resistance to both tamoxifen and the AI anastrozole, and these K303R MCF-7/Aro cells have an increase in the $\mathrm{Bcl}-2$ (anti-apoptotic)/Bax (pro-apoptotic) ratio, which is further exacerbated upon treatment with anastrozole [41].

The clonally selected long-term estrogen-deprived (LTED) models MCF-7:5C [42,43] and MCF-7:2A [44,45], used in our laboratory, have revealed some of the significant genetic reprogramming that occurs when the breast tumor cells are deprived of estrogen in the long term (>1 year) [46]. Notably, recent findings from our laboratory have identified a critical role for interferon-stimulated genes, in particular interferon-induced transmembrane protein 1 (IFITM1), which has been shown to be markedly overexpressed ( $>25$-fold) in AI-resistant MCF-7:5C breast cancer cells and AI-resistant breast tumors. Interestingly, we have found that overexpression of IFITM1 is strongly associated with enhanced cell survival, proliferation, and invasiveness of AI-resistant cells and that knockdown of IFITM1 induces cell death and blocks the ability of the resistant cells to migrate and invade [47].

\section{Noncoding RNAs and breast cancer}

The development and progression of breast cancer are affected by many factors, most of which involve a change in expression of certain genes. Of the mechanisms for regulating gene expression, ncRNAs have proven to be integral to the cell in recent studies [48]. ncRNAs include microRNA (miRNA), long noncoding RNA (lncRNA), transfer RNA, ribosomal RNA, and small nucleolar RNA. Two forms of ncRNA that are especially important for regulation of gene expression in cells are miRNA and lncRNA.

\section{microRNAs and breast cancer}

miRNAs are small RNA molecules of 18 to 22 base pairs that regulate the expression of target mRNAs by inhibiting translation or degrading the transcripts [49]. After
miRNA genes are initially transcribed by RNA polymerase II, a process regulated by transcription factors and nuclear receptors, the transcripts undergo significant processing both in the nucleus and cytoplasm (Figure 2) [50]. First, the pri-miRNA sequence is cleaved in the nucleus by Drosha, a class 2 RNase III enzyme that works in conjunction with DiGeorge syndrome chromosomal region 8 (DGCR8). The resulting pre-miRNA hairpin is exported from the nucleus to the cytoplasm via Exportin 5 where it is further cleaved by Dicer, another member of the RNase III family, resulting in a short doublestrand piece of RNA. The two strands of the RNA then separate into the passenger strand, which often gets degraded, and the mature miRNA strand, which binds to argonaute (Ago) proteins to form the RNA-induced silencing complex [49]. The miRNA of the RNA-induced silencing complex guides the complex to a complementary mRNA 3' untranslated region. Complementarity of the miRNA seed sequence (base pairs 2 to 7 ) to the target mRNA stimulates Ago2 in the RNA-induced silencing complex to degrade the mRNA [51]. However, if there is only partial complementarity, the translation of the mRNA will be inhibited.

Expression profiles of miRNA in breast tumor samples have been correlated with biopathologic features such as hormone receptor status and proliferation index, and are used to distinguish between basal and luminal subtypes $[52,53]$. For example, miRNAs overexpressed in basal, $E R \alpha$-negative primary breast cancers include miR-150, which has been shown to promote breast cancer growth [54], and miR-135b, which correlates with early metastasis of breast cancer cells [55]. miRNAs overexpressed in luminal, ER $\alpha$-positive breast cancers include miR-126 and miR-10a, which are associated with an increase in patients' relapse-free time after tamoxifen treatment [56].

Beyond the use of expression profiles, specific miRNAs have been associated with regulation of genes involved in breast cancer. The let-7 miRNA family has been shown to regulate the self-renewal capacity of breast tumor-initiating cells derived from cell lines and primary patient tumors by inhibition of HRAS and high mobility group AT-hook2 (HMGA2) - genes involved in self-renewal and differentiation, respectively [57]. miR-21, which targets phosphatase and tensin homolog (PTEN), was identified to be upregulated in primary patient samples of invasive breast cancer compared with normal breast tissue by miRNA in situ hybridization staining [58]. miR-373 and miR-520c are considered metastasis-promoting miRNAs and are shown to be upregulated in lymph node metastases compared with primary tumor samples [59]. Promotion of tumor invasion and metastasis by miR-373 and miR-520c is probably achieved via suppression of the CD44 gene, which codes for a hyaluronan receptor and has been identified as a metastasis suppressor in breast cancer [60]. 


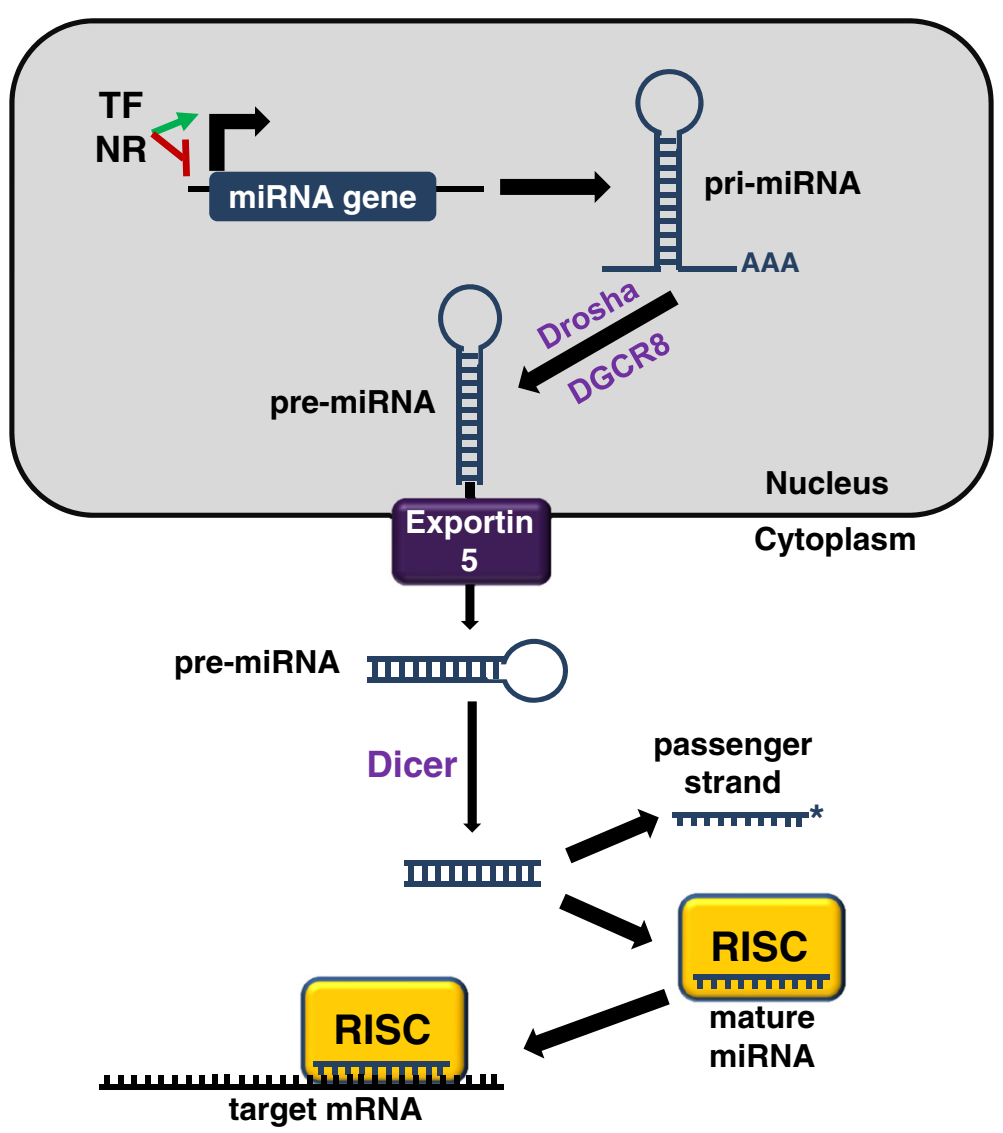

Figure 2 Standard pathway by which microRNAs are processed and loaded onto RISC to regulate gene expression. Regulation of microRNA (miRNA) expression is controlled at the miRNA promoter by transcription factors (TF) and nuclear receptors (NR). After transcription, the pri-miRNA is processed inside the nucleus by Drosha and DGCR8 to form pre-miRNA - a hairpin miRNA. Exportin 5 exports the pre-miRNA from the nucleus into the cytoplasm where it gets cleaved further by Dicer, resulting in a short double-strand piece of RNA. These strands are separated into the passenger strand, which often gets degraded, and the mature strand, which is loaded onto RNA-induced silencing complex (RISC) for action on target mRNA. If the seed sequence (base pairs 2 to 7 ) of the mature miRNA is complementary to the mRNA, the transcript is degraded. However, if there is not perfect complementarity between the miRNA seed sequence and its target mRNA, the result is inhibition of translation. DGCR8, DiGeorge syndrome chromosomal region 8.

For a more comprehensive look at the miRNAs involved in breast cancer, the reader should refer to reviews by O'Day and Lal and by Singh and Mo [61,62].

\section{Long noncoding RNAs and breast cancer}

lncRNAs are ncRNA transcripts longer than 200 base pairs that are transcribed from various genomic locations, such as in the promoters, enhancers, introns, or antisense coding regions of genes, or in their own stand-alone position in the genome (Figure 3A) [63]. Unlike miRNAs whose primary role is to repress the translation of their mRNA targets, IncRNAs have been shown to act as protein-DNA or protein-protein scaffolds, miRNA sponges, and protein decoys, as well as regulators of translation (Figure 3B) [64]. While previously thought of as junk DNA, lncRNAs are now regarded as an important part of the cell's gene regulation machinery, controlling cell cycle, apoptosis, and differentiation [65-67].

Some investigators have begun to identify lncRNAs whose expression is associated with aberrant signaling or unregulated survival of cancer cells. According to the IncRNADisease Database [68], there are 16 lncRNAs known to play a role in breast cancer including $\mathrm{H} 19$, growth arrest-specific 5 (GAS5), homeobox antisense intergenic RNA (HOTAIR), and breast cancer antiestrogen resistance 4 (BCAR4) [69-72].

The lncRNA H19, present on the maternal allele, normally plays a role in imprinted regions of the genome to silence insulin-like growth factor 2 (IGF2) [73]. H19 was said to have an oncogenic role in breast cancer cells in 2002, but has since been found to exhibit tumor suppressive action in vivo $[69,74]$. Hormonal regulation of $\mathrm{H} 19$ is important, as estradiol is able to stimulate H19 
A

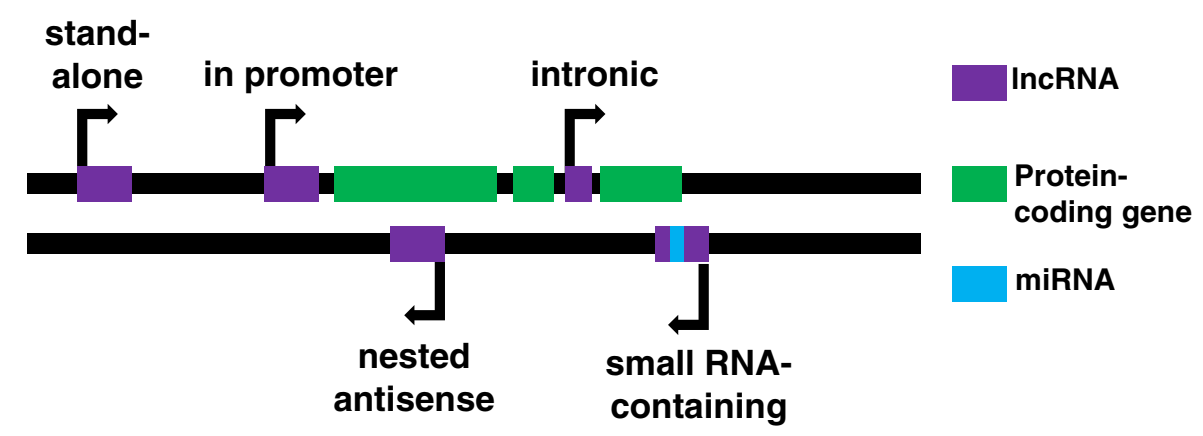

B

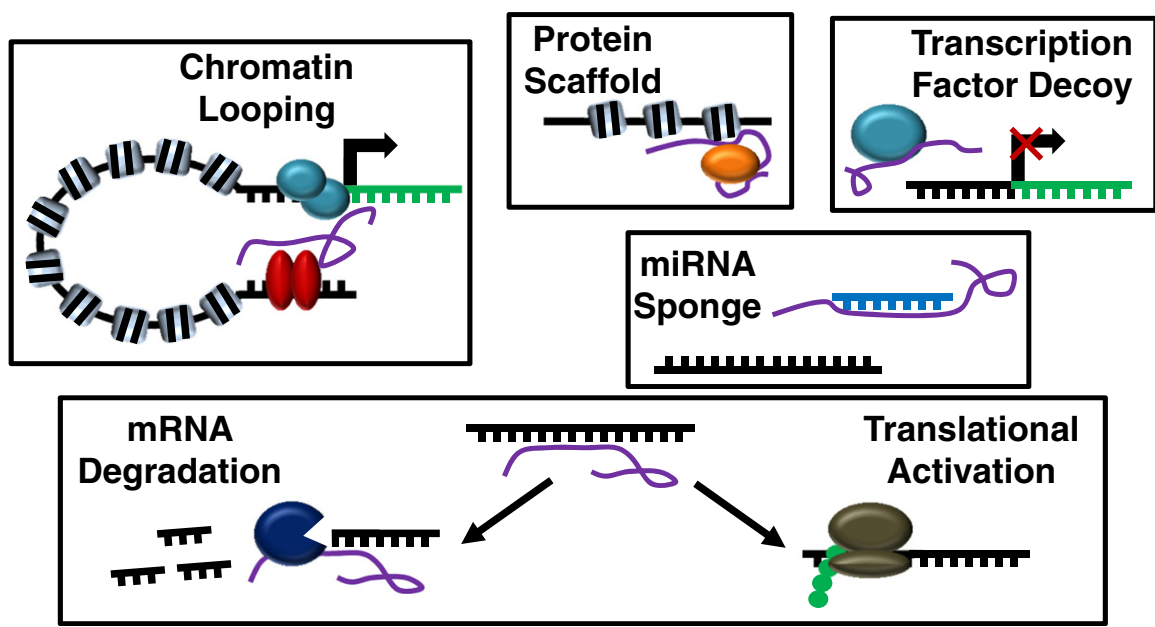

Figure 3 Location of long noncoding RNAs in the genome and roles of long noncoding RNAs in regulation of cellular processes. (A) Long noncoding RNA (IncRNA) genes reside in various genomic locations, such as in the promoters, enhancers, introns, or anti-sense coding regions of genes, and can also be in their own stand-alone position in the genome. These IncRNA genes sometimes contain small RNA genes, like microRNA (miRNA), that are spliced out of the IncRNA after transcription. (B) The actions of IncRNAs affect many cellular processes. IncRNAs may serve as scaffolds to bring nuclear receptors in contact with promoters of their target genes via chromatin looping, or they may recruit an epigenetic modifier to the chromatin. They can also bind proteins, such as transcription factors, to prevent their binding to DNA - similar to their mechanism of miRNA inhibition. Among the effects IncRNAs have on mRNA, translational activation and maintenance of mRNA stability are also important.

transcription in MCF-7 breast cancer cells, while tamoxifen inhibits this transcription [75].

GAS5 expression is downregulated in breast cancer samples relative to adjacent unaffected normal breast tissue, and has a distinct tumor suppressive role in breast cancer by inducing apoptosis and suppressing cell proliferation [70]. GAS5 acts primarily by preventing the glucocorticoid receptor from binding target DNA. Despite additional interactions with the androgen receptor and progesterone receptor, results show that GAS5 does not bind the ER [76].

HOTAIR was first identified as an lncRNA that regulates the homeobox $\mathrm{D}(H O X D)$ cluster by tethering the polycomb repressor complex 2 (PRC2) protein to the DNA at this site. PRC2 is able to promote histone H3K27 trimethylation and subsequent repression of transcription at the HOXD cluster, thereby preventing differentiation and leading to an invasive cellular phenotype [77]. Overexpression of HOTAIR has been associated with enhanced metastasis and invasion of breast cancer cells and can be used as a predictor of overall survival and progression-free survival [71]. A potential explanation for HOTAIR overexpression in breast cancer could be related to the presence of estrogen response elements in the HOTAIR promoter, leading to estradiol-induced HOTAIR expression [78].

Of the known lncRNAs associated with breast cancer, BCAR4 is most noteworthy for its role in endocrine resistance (see Long noncoding RNAs and tamoxifen resistance). 


\section{Noncoding RNAs and endocrine resistance microRNAs and tamoxifen resistance}

The miRNAs associated with endocrine resistance have been explored, and this effort has primarily focused on the differential expression of miRNAs in tamoxifenresistant cells. miRNAs that inhibit ER $\alpha$, such as miR-221/ 222 , are implicated in resistance to anti-ER $\alpha$ therapies. One study showed that ectopic expression of miR-221 or miR-222 was enough to decrease ER $\alpha$ protein expression in MCF-7 and T47D breast cancer cells, and this led to the cells acquiring resistance to tamoxifen (Figure 4A) [79]. In addition, silencing of miR-221 and miR-222 in ER $\alpha$-negative, endocrine-resistant MDAMB-468 breast cancer cells has been shown to increase
ER $\alpha$ expression and sensitize cells to tamoxifen-induced apoptosis [79].

In addition to targeting ER $\alpha$, miRNAs associated with tamoxifen resistance have been shown to regulate genes related to cell survival and metastasis. Following in vitro treatment of MCF-7 cells with tamoxifen there is an

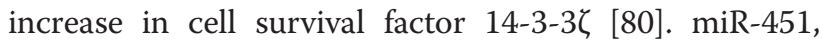
which normally targets the anti-apoptotic factors PI3K/

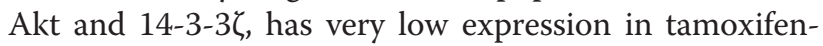
resistant MCF-7 cells, which could contribute to the survival of these cells after tamoxifen treatment (Figure 4A). In fact, re-expression of miR-451 has been shown to decrease cell proliferation and colony formation, as well as reduce HER2, epidermal growth factor receptor, and
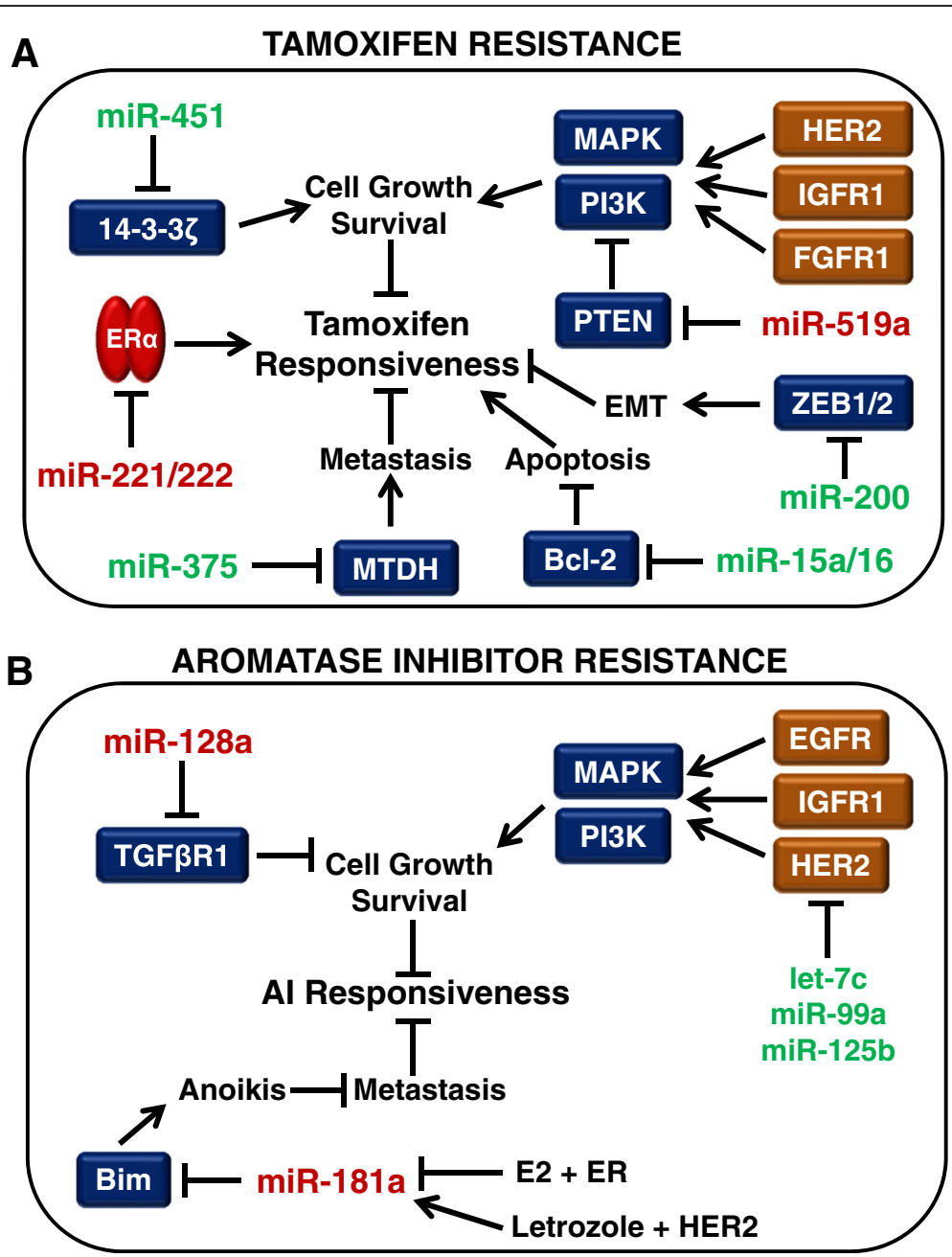

Figure 4 Role of microRNA in endocrine resistance. microRNAs (miRNAs) that regulate the growth, survival, apoptosis, epithelial-to-mesenchymal transition (EMT), and metastasis of breast cancer cells are implicated in the loss of responsiveness to endocrine therapies. miRNAs that are upregulated in endocrine resistance (red) could potentially be targets of RNA interference therapies, while miRNAs that are downregulated in endocrine resistance (green) could be targets of a replacement therapy in endocrine-resistant breast tumors. (A) miRNAs involved in tamoxifen resistance. (B) miRNAs involved in aromatase inhibitor (AI) resistance. Bim, BCl-2-like 11; EGFR, epidermal growth factor receptor; ER, estrogen receptor; E2, 17ß-estradiol; FGFR1, fibroblast growth factor receptor 1; HER2, human epidermal growth factor receptor 2; IGFR1, insulin-like growth factor receptor 1; MAPK, mitogen-activated protein kinase; MTDH, metadherin; PI3K, phosphoinositide 3-kinase; PTEN, phosphatase and tensin homolog; TGFR1 $\beta$, transforming growth factor beta receptor 1; ZEB1/2, zinc finger E box-binding homeobox 1/2. 
MAPK levels, followed by a restored sensitivity to tamoxifen in resistant MCF-7 cells [80]. There is also evidence that miR-451 expression is reduced in doxorubicinresistant MCF-7 breast cancer cells and that it regulates the drug transporter P-glycoprotein/MDR1 in these cells [81]. Both tamoxifen and 4-hydroxytamoxifen are known to bind to P-glycoprotein, and endoxifen has been shown to be a substrate of this transporter, thus suggesting the importance of this efflux transporter to tamoxifen therapy $[82,83]$.

In another tamoxifen-resistant cell model (MCF-7/ TAMR), miR-375 was identified as one of the top downregulated miRNAs. Re-expression of miR-375 was enough to reverse the tamoxifen-resistant phenotype via repression of metadherin $(M T D H)$, a metastasis-promoting cell surface protein (Figure 4A) [84]. Expression of MTDH and miR-375 were inversely correlated in primary breast cancer samples, and survival data from tamoxifen-treated patients revealed that higher expression of MTDH was associated with a shorter disease-free survival and higher risk of relapse [84]. Another recent study of miRNA in the tamoxifen-resistant MCF-7 TamR cells has revealed upregulation of the C19MC cluster, a primate-specific cluster of 19 miRNAs, with miR-519a being most highly overexpressed [85]. miR-519a was shown to directly target the tumor suppressor genes CDKN1A (P21), PTEN, and $R B 1$, allowing for the enhanced signaling of the PI3K growth and survival pathway in tamoxifen-resistant cells (Figure 4A).

MCF-7 cells expressing an oncogenic isoform of HER2 (MCF-7/HER2 $\Delta 16)$ evade tamoxifen treatment by upregulating the expression of the anti-apoptotic factor $\mathrm{Bcl}-2$ and downregulating the expression of miR-15a/16, which inhibit expression of Bcl-2 [86]. Treatment of the MCF-7/HER2 $\triangle 16$ cells with exogenous miR-15a/16 decreased tamoxifen-induced Bcl-2 levels and re-sensitized the cells to tamoxifen-induced cell death [86]. These MCF-7/HER $2 \Delta 16$ cells also present decreased expression of miR-342, which was shown to regulate expression of genes involved in breast tumor cell cycle progression, such as cyclin B1, p53, and breast cancer 1 (BRCA1) [87]. miR-342 expression was also shown to be downregulated in tamoxifen refractory human breast tumors, which confirms its clinical relevance [87].

Other miRNAs that play a role in tamoxifen resistance include members of the miR-200 family - miR-200a, miR200b, and miR-200c, all of which inhibit the expression of zinc finger Ebox-binding homeobox 1/2 (ZEB1/2) [88]. The miR-200 family has been shown to be expressed at low levels in tamoxifen-resistant LY2 breast cancer cells compared with tamoxifen-sensitive MCF-7 parental cells (Figure 4A). ZEB1/2-mediated transcriptional repression of E-cadherin is necessary for epithelial-to-mesenchymal transition, so the upregulation of ZEB1/2 could contribute to the invasiveness of tamoxifen-resistant breast cancer cells. Overexpression of the miR-200 family members has been shown to inhibit cell migration and reverse epithelial-to-mesenchymal transition [88].

In a study of $235 \mathrm{ER} \alpha$-positive breast cancer specimens, high expression of miR-26a was significantly associated with clinical benefit and prolonged time to progression. A combination of high miR-26a expression and low expression of the miR-26a targets cyclin-dependent kinase 1 $(C D C 2)$ and cyclin E1 (CCNE1) was associated with favorable outcome after tamoxifen treatment [89]. Another study measured the expression of five miRNAs in 246 ER $\alpha$-positive primary breast cancer tumors from patients treated with tamoxifen for advanced disease and found that high expression of miR-30a, miR-30c, and miR-182 was significantly associated with tamoxifen sensitivity and longer progression-free survival [90]. miR-30c was the most significant and independent predictor of clinical benefit, and correlated positively with ER $\alpha$ and inversely with epidermal growth factor receptor [90]. Lastly, analysis of miRNA expression in matched samples from ER $\alpha$-positive breast cancer patients treated with tamoxifen indicated that high expression of miR-126 and miR-10a were associated with an increase in patients' relapse-free time after tamoxifen treatment [56]. Additionally, miR-126 has been shown to suppress metastasis of breast cancers in subtype-specific mechanisms that involve inhibiting infiltration of mesenchymal stem cells and inflammatory monocytes [91].

\section{Long noncoding RNAs and tamoxifen resistance}

The IncRNA BCAR4 was discovered in a functional screen of ZR-75-1 breast cancer cells to identify mechanisms of anti-estrogen resistance [92]. Overexpression of BCAR4 in tamoxifen-sensitive ZR-75-1 cells blocked the anti-proliferative effects of tamoxifen, and BCAR4 has since been shown to be a clinically relevant biomarker for increased invasiveness and tamoxifen resistance [72,92]. The role of BCAR4 in tamoxifen resistance relies on the coexpression of HER2, but is independent of ER $\alpha[93,94]$. A HER2 inhibitor may thus be ideal for those patients whose tumors are resistant to traditional endocrine therapy due to high levels of BCAR4, and are accompanied by HER2 overexpression. However, if a method of RNA interference is developed to diminish levels of BCAR4 in breast cancer patients, this could also be a rational therapy. When it is not present at high levels in breast tumors, BCAR4 is normally found only in the human placenta and oocyte, diminishing the side effects of such a therapy [93].

\section{microRNAs and aromatase inhibitor resistance}

The topic of miRNAs involved in AI resistance is newer than that of miRNAs in tamoxifen resistance, but recent studies have started to shed light on the field. Masri and 
colleagues conducted a miRNA expression analysis for four AI-resistant cell models, all derived from aromataseoverexpressing MCF-7aro cells [95]. MCF-7aro cells were treated with testosterone and each of three AIs until they acquired resistance. An LTED cell line (LTEDaro) was also derived from the MCF-7aro cells for comparison. When compared with LTEDaro cells and cells treated only with testosterone, letrozole-resistant cells overexpressed miR$128 \mathrm{a}$ - suggesting miR-128a plays a role in AI resistance. miR-128a is associated with breast cancer aggressiveness, and is involved in regulation of transforming growth factor beta receptor 1 (Figure 4B) [96]. Inhibition of miR128a in the letrozole-resistant cells led to resensitization to transforming growth factor beta growth-inhibitory effects [95]. It is also interesting to note that the expression profiles for the cells resistant to the steroidal AI (exemestane) and the nonsteroidal AIs (letrozole, anastrozole) were distinct from one another, and the AI-resistant cells were distinct from the LTEDaro model of AI resistance, which supports the idea that multiple mechanisms of acquired resistance to AIs may exist [95].

Unpublished data from our laboratory have given additional insight into the miRNAs that may be involved in the AI-resistant phenotype. Next-generation sequencing of miRNA in MCF-7 cells, MCF-7:5C (LTED) cells, and MCF-7:2A (LTED) cells has revealed over 120 miRNAs whose expression levels are altered in both the MCF7:5C and MCF-7:2A cells compared with the parental MCF-7 cells. One of the most interesting results is that both MCF-7:5C and MCF-7:2A cells show an increase in miR-181a, which targets Bcl-2-like 11 (Bim), a proapoptotic protein involved in anoikis (cell death) after breast cancer cells detach from the basement membrane in preparation for metastasis (Figure 4B) [97]. Recent work from Angela Brodie's laboratory indicates a HER2dependent upregulation of miR-181a in letrozole-resistant ER $\alpha$-negative/HER2-positive breast cancer cells, and indicates that miR-181a expression is increased in ER $\alpha$ negative/HER2-positive and ER $\alpha$-positive/HER2-positive clinical samples [98]. Several miRNAs have been described as estrogen responsive, and this information is important when studying estrogen-deprived cells in these AIresistant tumors [99]. Thus, it is worth noting that miR181a is downregulated upon estrogen treatment, which might explain its overexpression in the LTED cells [100].

In addition to the confirmed role of miR-128a, Masri and colleagues also briefly mentioned the downregulation of miR-125b in the letrozole-resistant, anastrozoleresistant, and exemestane-resistant cells compared with the LTEDaro cells [95]. A recent study in MCF-7:2A (LTED) cells confirms downregulation of miR-125b in this AI-resistant LTED model and also indicates relevance of the other members of its miRNA cluster [101]. The let-7c/miR-99a/miR-125b miRNA cluster encoded within the LINC00487 gene was shown to be downregulated in MCF-7:2A cells compared with MCF-7 parental cells. A luciferase reporter assay confirmed that let-7c and miR-125b bind the HER2 3' untranslated region, but it was revealed that while miR-125b directly regulates HER2 expression via the binding of HER2 3' untranslated region, let-7c regulation of HER2 is indirect via the inhibition of Dicer, one of the proteins involved in miRNA function [101]. Upon analysis of clinical data from The Cancer Genome Atlas, it was clear that let-7c and HER2 were inversely correlated in luminal A breast tumors and that low expression of the let-7c/miR-99a/ miR-125b cluster was associated with worse overall survival compared with patients who had high expression of this cluster [101].

Proposed roles of miRNA in AI resistance can be also determined by focusing on miRNAs that have shown importance in estrogen-independent growth and survival or are differentially expressed following anti-estrogen therapy. An in vivo selection process using a miRNA library revealed six miRNAs that were shown to confer estrogen-independent growth and increased phosphorylatedAkt in MCF-7 breast cancer cells [102]. Of these six, miR101 was capable of promoting estrogen-independent growth, while the other five were not. Further characterization of miR-101 revealed that it inhibits expression of membrane-associated guanylate kinase (MAGI-2), a protein necessary for PTEN activity [102]. Expression of miR-101 is thus important for estrogen-independent growth mediated by the PI3K/Akt pathway, which could be important for resistance to both tamoxifen and AIs.

In a study to identify estrogen-regulated miRNAs, a group of miRNAs was shown to have elevated expression upon combined treatment of tamoxifen and exemestane, including miR-21, miR-181b, miR-26a/b, miR27b, and miR-23b [100]. As discussed earlier, miR-21 is upregulated in primary patient samples of invasive breast cancer compared with normal breast tissue, and miR-26a is associated with favorable outcome after tamoxifen treatment $[58,89]$. While these miRNAs have not been directly implicated in AI resistance, their overexpression after treatment makes them candidates for a role in survival of AI-resistant cells. Likewise, a study of miRNA expression in MCF-7 cells revealed several miRNAs that are increased following letrozole treatment [103]. Perhaps the most interesting result was the upregulation of let-7f upon treatment with letrozole, as it inhibits the expression of the aromatase gene (CYP19A1) [103]. This study may reveal a mechanism of resistance similar to that of tamoxifen resistance - loss of the inhibitor's target. Just as tamoxifen resistance occurs in conjunction with absence of ER $\alpha$, resistance to AIs may eventually develop due to pronounced loss of aromatase 
expression due to upregulation of certain miRNAs upon treatment.

\section{Long noncoding RNAs and aromatase inhibitor resistance} There have been few studies that have focused specifically on the role of lncRNA in AI resistance. Nevertheless, there is some evidence that the lncRNAs regulating steroid receptors such as ER $\alpha$ may play a role in resistance. It has been shown that the lncRNA steroid receptor RNA activator 1 (SRA1) acts as a coactivator of ER $\alpha$, and this action depends on the phosphorylation of ER $\alpha$ at Ser118 [104]. When this phosphorylation event occurs via the kinase action of MAPK (a protein that is often upregulated in AI-resistant cells), it is associated with estrogen-independent activation of ER $\alpha$ [6]. This putative mechanism of resistance is similar to that of AIB1 and tamoxifen resistance - just as AIB1 coactivates ER $\alpha$ in the presence of tamoxifen and this is enhanced by the presence of HER2, SRA1 could potentially coactivate $\mathrm{ER} \alpha$ in an AI-induced estrogen-deprived environment, and this requires MAPK activity.

The scaffolding lncRNAs prostate cancer associated noncoding RNA 1 (PRNCR1) and prostate-specific transcript 1 (PCGEM1) have previously been reported to play a role in transcription of androgen receptor target genes in the androgen-resistant prostate cancer cell lines CWR22Rv1 and LNCaP-cds1/2 via a chromatin-looping mechanism involving the androgen receptor [105]. A more recent study by Prensner and colleagues, however, refutes that PCGEM1 and PRNCR1 interact with the androgen receptor and that either gene is a component of androgen receptor signaling or is involved in castrationresistant prostate cancer [106]. There were differences between the two studies, which might partially explain the conflicting observations reported. Prensner and coworkers analyzed castration-resistant prostate tumor samples that were collected from high-risk prostate cancer patients but they did not evaluate castration-resistant prostate cancer cell lines, whereas the study by Yang and coworkers evaluated castration-resistant prostate tumor samples as well as castration-resistant prostate cancer cell lines. Overall, despite the inconclusive results from these two studies, they still offer insight into a possible chromatin-looping mechanism by which lncRNAs could facilitate the transcription of ER $\alpha$ target genes in the absence of estrogen in breast cancer cells that have acquired AI resistance.

\section{Conclusions}

In summary, there are numerous ncRNAs shown to be involved in acquired resistance to endocrine therapies. ncRNAs provide an exciting avenue of gene regulation that has not yet been fully explored. As we uncover the miRNAs and lncRNAs involved in specific disease states, such as resistance to breast cancer treatments, it will be possible to use these RNAs as both therapeutic targets and biomarkers.

Regarding therapeutic approaches, oncogenic ncRNAs that contribute to the progression of disease would need to be eliminated via RNA interference, while tumorsuppressive ncRNAs may be part of replacement therapies. There are over 20 RNA interference-based therapies employing various methods of small interfering RNA delivery currently in phase I clinical trials for the treatment of diseases such as viral infections, hereditary disorders, and cancer [107]. The only RNA replacement clinical trial to date began in April 2013 as a strategy to deliver miR-34, a tumor-suppressive miRNA that regulates expression of $B C L-2$ and $M Y C$, to patients with liver-based cancers [108]. Although there are not yet published results on this MRX34 treatment, a recent update revealed that MRX34 has a manageable safety profile with only one incidence of a dose-limiting toxicity [109].

With the use of innovative technologies, it is now possible to use ncRNAs as biomarkers and compile biomarker panels for diagnosis and prognosis of diseases, including cancer. Circulating miRNAs are ideal for clinical use, since they are highly stable and can be detected by a non-invasive manner in a blood sample. Circulating miRNA levels in breast cancer patients have been studied at diagnosis, in early stage tumors, after surgical resection, following chemotherapy/radiation treatments, and following metastatic relapse - all to understand the unique miRNA profiles throughout the progression of breast cancer [110-112]. Because of the low abundance of miRNAs in the blood, the use of powerful detection methods such as high-throughput sequencing will need to be employed in clinical settings. A more complete picture of the differentially expressed regulatory RNAs is crucial for the development of these therapeutic strategies and biomarker signatures, especially in a disease as complex as breast cancer.

\begin{abstract}
Abbreviations
Ago: Argonaute; Al: Aromatase inhibitor; AIB1: Amplified in breast cancer 1; Akt: Protein kinase B; BCAR4: Breast cancer anti-estrogen resistance 4; ER: Estrogen receptor; GAS5: Growth arrest-specific 5; HER2: Human epidermal growth factor receptor 2; HOTAIR: Homeobox antisense intergenic RNA; HOXD: Homeobox D; IFITM1: Interferon-induced transmembrane protein 1; IncRNA: Long noncoding RNA; LTED: Long-term estrogen-deprived; MAPK: Mitogen-activated protein kinase; MDR1: Multi-drug resistance protein 1; miRNA: microRNA; MTDH: Metadherin; ncRNA: Noncoding RNA;

PCGEM1: Prostate-specific transcript 1; PI3K: Phosphoinositide 3-kinase; PRC2: Polycomb repressor complex 2; PRNCR1: Prostate cancer associated noncoding RNA 1; PTEN: Phosphatase and tensin homolog; SRA1: Steroid receptor RNA activator 1; ZEB1/2: Zinc finger E box-binding homeobox 1/2.
\end{abstract}

Competing interests

The authors declare that they have no competing interests.

\section{Acknowledgements}

This work was supported by grants from the Department of Defense (W81XWH-12-1-0139; supporting JSL-W), the National Cancer Institute 
(K01CA120051; supporting JSL-W), the National Science Foundation Graduate Research Fellowship (QH866640; supporting ELH) and by start-up funds from the University of Kansas Medical Center (supporting JSL-W and ELH).

\section{Received: 12 September 2014 Accepted: 19 February 2015} Published online: 17 March 2015

\section{References}

1. American Cancer Society. Cancer Facts \& Figures 2014. Atlanta: American Cancer Society; 2014.

2. Stanford JL, Szklo M, Brinton LA. Estrogen receptors and breast cancer. Epidemiol Rev. 1986;8:42-59.

3. Beato $M$, Herrlich $P$, Schutz G. Steroid hormone receptors: many actors in search of a plot. Cell. 1995;83:851-7.

4. Tsai MJ, O'Malley BW. Molecular mechanisms of action of steroid/thyroid receptor superfamily members. Annu Rev Biochem. 1994;63:451-86.

5. Kumar V, Green S, Stack G, Berry M, Jin JR, Chambon P. Functional domains of the human estrogen receptor. Cell. 1987;51:941-51.

6. Kato S, Endoh H, Masuhiro Y, Kitamoto T, Uchiyama S, Sasaki H, et al. Activation of the estrogen receptor through phosphorylation by mitogenactivated protein kinase. Science. 1995;270:1491-4.

7. Vilgelm A, Lian Z, Wang H, Beauparlant SL, Klein-Szanto A, Ellenson LH, et al. Akt-mediated phosphorylation and activation of estrogen receptor alpha is required for endometrial neoplastic transformation in Pten+/- mice. Cancer Res. 2006;66:3375-80.

8. Hall JM, Couse JF, Korach KS. The multifaceted mechanisms of estradiol and estrogen receptor signaling. J Biol Chem. 2001;276:36869-72.

9. Nilsson S, Makela S, Treuter E, Tujague M, Thomsen J, Andersson G, et al. Mechanisms of estrogen action. Physiol Rev. 2001;81:1535-65.

10. Levin ER. Integration of the extranuclear and nuclear actions of estrogen. Mol Endocrinol. 2005;19:1951-9.

11. Davies C, Pan H, Godwin J, Gray R, Arriagada R, Raina V, et al. Long-term effects of continuing adjuvant tamoxifen to 10 years versus stopping at 5 years after diagnosis of oestrogen receptor-positive breast cancer: ATLAS, a randomised trial. Lancet. 2013;381:805-16.

12. Fisher B, Costantino JP, Wickerham DL, Redmond CK, Kavanah M, Cronin WM, et al. Tamoxifen for prevention of breast cancer: report of the National Surgical Adjuvant Breast and Bowel Project P-1 Study. J Natl Cancer Inst. 1998;90:1371-88.

13. Tate AC, Greene GL, DeSombre ER, Jensen EV, Jordan VC. Differences between estrogen- and antiestrogen-estrogen receptor complexes from human breast tumors identified with an antibody raised against the estrogen receptor. Cancer Res. 1984:44:1012-8.

14. Bross PF, Cohen MH, Williams GA, Pazdur R. FDA drug approval summaries: fulvestrant. Oncologist. 2002;7:477-80.

15. Simpson ER, Mahendroo MS, Means GD, Kilgore MW, Hinshelwood MM, Graham-Lorence S, et al. Aromatase cytochrome P450, the enzyme responsible for estrogen biosynthesis. Endocrine Rev. 1994;15:342-55.

16. Simpson ER. Sources of estrogen and their importance. J Steroid Biochem Mol Biol. 2003;86:225-30

17. Chumsri S, Howes T, Bao T, Sabnis G, Brodie A. Aromatase, aromatase inhibitors, and breast cancer. J Steroid Biochem Mol Biol. 2011;125:13-22.

18. Geisler J, Haynes B, Anker G, Dowsett M, Lonning PE. Influence of letrozole and anastrozole on total body aromatization and plasma estrogen levels in postmenopausal breast cancer patients evaluated in a randomized, crossover study. J Clin Oncol. 2002;20:751-7.

19. Geisler J, King N, Anker G, Ornati G, Di Salle E, Lonning PE, et al. In vivo inhibition of aromatization by exemestane, a novel irreversible aromatase inhibitor, in postmenopausal breast cancer patients. Clin Cancer Res. 1998;4:2089-93.

20. Shou J, Massarweh S, Osborne CK, Wakeling AE, Ali S, Weiss H, et al. Mechanisms of tamoxifen resistance: increased estrogen receptor-HER2/neu cross-talk in ER/HER2-positive breast cancer. J Natl Cancer Inst. 2004:96:926-35.

21. Gottardis MM, Jordan VC. Development of tamoxifen-stimulated growth of MCF-7 tumors in athymic mice after long-term antiestrogen administration. Cancer Res. 1988;48:5183-7.

22. Smith CL, Nawaz Z, O'Malley BW. Coactivator and corepressor regulation of the agonist/antagonist activity of the mixed antiestrogen, 4hydroxytamoxifen. Mol Endocrinol. 1997;11:657-66.

23. Osborne CK, Bardou V, Hopp TA, Chamness GC, Hilsenbeck SG, Fuqua SA, et al. Role of the estrogen receptor coactivator AIB1 (SRC-3) and HER-2/neu in tamoxifen resistance in breast cancer. J Natl Cancer Inst. 2003;95:353-61.
24. Zhang $Y$, Moerkens M, Ramaiahgari S, de Bont H, Price L, Meerman J, et al. Elevated insulin-like growth factor 1 receptor signaling induces antiestrogen resistance through the MAPK/ERK and PI3K/Akt signaling routes. Breast Cancer Res. 2011;13:R52.

25. Turner N, Pearson A, Sharpe R, Lambros M, Geyer F, Lopez-Garcia MA, et al. FGFR1 amplification drives endocrine therapy resistance and is a therapeutic target in breast cancer. Cancer Res. 2010;70:2085-94.

26. Sharma D, Blum J, Yang X, Beaulieu N, Macleod AR, Davidson NE. Release of methyl CpG binding proteins and histone deacetylase 1 from the estrogen receptor alpha (ER) promoter upon reactivation in ER-negative human breast cancer cells. Mol Endocrinol. 2005;19:1740-51.

27. Desta Z, Ward BA, Soukhova NV, Flockhart DA. Comprehensive evaluation of tamoxifen sequential biotransformation by the human cytochrome P450 system in vitro: prominent roles for CYP3A and CYP2D6. J Pharmacol Exp Ther. 2004;310:1062-75.

28. $X u$ Y, Sun $Y$, Yao L, Shi L, Wu Y, Ouyang T, et al. Association between CYP2D6 ${ }^{*} 10$ genotype and survival of breast cancer patients receiving tamoxifen treatment. Ann Oncol. 2008;19:1423-9.

29. Goetz MP, Rae JM, Suman VJ, Safgren SL, Ames MM, Visscher DW, et al. Pharmacogenetics of tamoxifen biotransformation is associated with clinical outcomes of efficacy and hot flashes. J Clin Oncol. 2005;23:9312-8.

30. Clarke R, Skaar TC, Bouker KB, Davis N, Lee YR, Welch JN, et al. Molecular and pharmacological aspects of antiestrogen resistance. J Steroid Biochem Mol Biol. 2001;76:71-84.

31. Tsukamoto F, Shiba E, Taguchi T, Sugimoto T, Watanabe T, Kim SJ, et al. Immunohistochemical detection of P-glycoprotein in breast cancer and its significance as a prognostic factor. Breast Cancer. 1997:4:259-63.

32. Larkin A, O'Driscoll L, Kennedy S, Purcell R, Moran E, Crown J, et al. Investigation of MRP-1 protein and MDR-1 P-glycoprotein expression in invasive breast cancer: a prognostic study. Int J Cancer. 2004;112:286-94.

33. Jelovac D, Sabnis G, Long BJ, Macedo L, Goloubeva OG, Brodie AM. Activation of mitogen-activated protein kinase in xenografts and cells during prolonged treatment with aromatase inhibitor letrozole. Cancer Res. 2005;65:5380-9.

34. Gilani RA, Kazi AA, Shah P, Schech AJ, Chumsri S, Sabnis G, et al. The importance of HER2 signaling in the tumor-initiating cell population in aromatase inhibitor-resistant breast cancer. Breast Cancer Res Treat. 2012;135:681-92

35. Burris 3rd HA. Overcoming acquired resistance to anticancer therapy: focus on the PI3K/KT/mTOR pathway. Cancer Chemother Pharmacol. 2013;71:829-42.

36. Robinson DR, Wu YM, Vats P, Su F, Lonigro RJ, Cao X, et al. Activating ESR1 mutations in hormone-resistant metastatic breast cancer. Nat Genet. 2013:45:1446-51.

37. Jansen MP, Knijnenburg T, Reijm EA, Simon I, Kerkhoven R, Droog M, et al. Hallmarks of aromatase inhibitor drug resistance revealed by epigenetic profiling in breast cancer. Cancer Res. 2013;73:6632-41.

38. Garcia-Becerra R, Santos N, Diaz L, Camacho J. Mechanisms of resistance to endocrine therapy in breast cancer: focus on signaling pathways, miRNAs and genetically based resistance. Int J Mol Sci. 2012;14:108-45.

39. Chen S. An 'omics' approach to determine the mechanisms of acquired aromatase inhibitor resistance. Omics. 2011;15:347-52.

40. Thiantanawat A, Long BJ, Brodie AM. Signaling pathways of apoptosis activated by aromatase inhibitors and antiestrogens. Cancer Res. 2003;63:8037-50.

41. Barone I, Cui Y, Herynk MH, Corona-Rodriguez A, Giordano C, Selever J, et al Expression of the K303R estrogen receptor-alpha breast cancer mutation induces resistance to an aromatase inhibitor via addiction to the PI3K Akt kinase pathway. Cancer Res. 2009;69:4724-32.

42. Jiang SY, Wolf DM, Yingling JM, Chang C, Jordan VC. An estrogen receptor positive MCF-7 clone that is resistant to antiestrogens and estradiol. Mol Cell Endocrinol. 1992;90:77-86.

43. Lewis JS, Meeke K, Osipo C, Ross EA, Kidawi N, Li T, et al. Intrinsic mechanism of estradiol-induced apoptosis in breast cancer cells resistant to estrogen deprivation. J Natl Cancer Inst. 2005;97:1746-59.

44. Pink JJ, Jiang SY, Fritsch M, Jordan VC. An estrogen-independent MCF-7 breast cancer cell line which contains a novel 80-kilodalton estrogen receptor-related protein. Cancer Res. 1995;55:2583-90.

45. Lewis-Wambi JS, Swaby R, Kim H, Jordan VC. Potential of L-buthionine sulfoximine to enhance the apoptotic action of estradiol to reverse acquired antihormonal resistance in metastatic breast cancer. J Steroid Biochem Mol Biol. 2009;114:33-9. 
46. Ariazi EA, Cunliffe HE, Lewis-Wambi JS, Slifker MJ, Willis AL, Ramos P, et al. Estrogen induces apoptosis in estrogen deprivation-resistant breast cancer through stress responses as identified by global gene expression across time. Proc Natl Acad Sci U S A. 2011:108:18879-86.

47. Choi HJ, Lui A, Ogony J, Jan R, Sims PJ, Lewis-Wambi J. Targeting interferon response genes sensitizes aromatase inhibitor resistant breast cancer cells to estrogen-induced cell death. Breast Cancer Res. 2015;17:6 [Epub ahead of print].

48. Morris KV, Mattick JS. The rise of regulatory RNA. Nat Rev Genet. 2014;15:423-37.

49. He L, Hannon GJ. MicroRNAs: small RNAs with a big role in gene regulation. Nat Rev Genet. 2004;5:522-31.

50. Krol J, Loedige I, Filipowicz W. The widespread regulation of microRNA biogenesis, function and decay. Nat Rev Genet. 2010;11:597-610.

51. Meister G, Landthaler M, Patkaniowska A, Dorsett $Y$, Teng G, Tuschl T. Human Argonaute2 mediates RNA cleavage targeted by miRNAs and siRNAs. Mol Cell. 2004;15:185-97.

52. Blenkiron C, Goldstein LD, Thorne NP, Spiteri I, Chin SF, Dunning MJ, et al. MicroRNA expression profiling of human breast cancer identifies new markers of tumor subtype. Genome Biol. 2007:8:R214

53. Iorio MV, Ferracin M, Liu CG, Veronese A, Spizzo R, Sabbioni S, et al. MicroRNA gene expression deregulation in human breast cancer. Cancer Res. 2005;65:7065-70.

54. Huang S, Chen Y, Wu W, Ouyang N, Chen J, Li H, et al. miR-150 promotes human breast cancer growth and malignant behavior by targeting the pro-apoptotic purinergic P2X7 receptor. PLoS One. 2013;8:e80707.

55. Arigoni M, Barutello G, Riccardo F, Ercole E, Cantarella D, Orso F, et al. miR-135b coordinates progression of ErbB2-driven mammary carcinomas through suppression of MID1 and MTCH2. Am J Pathol. 2013;182:2058-70.

56. Hoppe R, Achinger-Kawecka J, Winter S, Fritz P, Lo WY, Schroth W, et al. Increased expression of miR-126 and miR-10a predict prolonged relapsefree time of primary oestrogen receptor-positive breast cancer following tamoxifen treatment. Eur J Cancer. 2013:49:3598-608.

57. Yu F, Yao H, Zhu P, Zhang X, Pan Q, Gong C, et al. let-7 regulates self renewal and tumorigenicity of breast cancer cells. Cell. 2007;131:1109-23.

58. Qi L, Bart J, Tan LP, Platteel I, Sluis T, Huitema S, et al. Expression of miR-21 and its targets (PTEN, PDCD4, TM1) in flat epithelial atypia of the breast in relation to ductal carcinoma in situ and invasive carcinoma. BMC Cancer. 2009;9:163.

59. Huang Q, Gumireddy K, Schrier M, le Sage C, Nagel R, Nair S, et al. The microRNAs miR-373 and miR-520c promote tumour invasion and metastasis. Nat Cell Biol. 2008;10:202-10.

60. Lopez Jl, Camenisch TD, Stevens MV, Sands BJ, McDonald J, Schroeder JA. CD44 attenuates metastatic invasion during breast cancer progression. Cancer Res. 2005;65:6755-63.

61. O'Day E, Lal A. MicroRNAs and their target gene networks in breast cancer Breast Cancer Res. 2010;12:201.

62. Singh $\mathrm{R}, \mathrm{Mo} \mathrm{YY}$. Role of microRNAs in breast cancer. Cancer Biol Ther. 2013;14:201-12.

63. Kung JT, Colognori D, Lee JT. Long noncoding RNAs: past, present, and future. Genetics. 2013;193:651-69.

64. Hu W, Alvarez-Dominguez JR, Lodish HF. Regulation of mammalian cell differentiation by long non-coding RNAs. EMBO Rep. 2012;13:971-83.

65. Kitagawa M, Kitagawa K, Kotake Y, Niida H, Ohhata T. Cell cycle regulation by long non-coding RNAs. Cell Mol Life Sci. 2013;70:4785-94.

66. Rossi MN, Antonangeli F. LncRNAs: new players in apoptosis control. Int J Cell Biol. 2014;2014:473857.

67. lyengar BR, Choudhary A, Sarangdhar MA, Venkatesh KV, Gadgil CJ, Pillai B. Non-coding RNA interact to regulate neuronal development and function. Front Cell Neurosci. 2014;8:47

68. Chen G, Wang Z, Wang D, Qiu C, Liu M, Chen X, et al. LncRNADisease: a database for long-non-coding RNA-associated diseases. Nucleic Acids Res. 2013:41:D983-6.

69. Lottin S, Adriaenssens E, Dupressoir T, Berteaux N, Montpellier C, Coll J, et al. Overexpression of an ectopic $\mathrm{H} 19$ gene enhances the tumorigenic properties of breast cancer cells. Carcinogenesis. 2002;23:1885-95.

70. Mourtada-Maarabouni M, Pickard MR, Hedge VL, Farzaneh F, Williams GT. GAS5, a non-protein-coding RNA, controls apoptosis and is downregulated in breast cancer. Oncogene. 2009;28:195-208.

71. Gupta RA, Shah N, Wang KC, Kim J, Horlings HM, Wong DJ, et al. Long noncoding RNA HOTAIR reprograms chromatin state to promote cancer metastasis. Nature. 2010;464:1071-6.
72. Godinho MF, Sieuwerts AM, Look MP, Meijer D, Foekens JA, Dorssers LC, et al. Relevance of BCAR4 in tamoxifen resistance and tumour aggressiveness of human breast cancer. Br J Cancer. 2010;103:1284-91.

73. Weksberg R, Nishikawa J, Caluseriu O, Fei YL, Shuman C, Wei C, et al. Tumor development in the Beckwith-Wiedemann syndrome is associated with a variety of constitutional molecular 11p15 alterations including imprinting defects of KCNQ1OT1. Hum Mol Genet. 2001;10:2989-3000.

74. Yoshimizu T, Miroglio A, Ripoche MA, Gabory A, Vernucci M, Riccio A, et al. The H19 locus acts in vivo as a tumor suppressor. Proc Natl Acad Sci U S A. 2008;105:12417-22

75. Adriaenssens E, Lottin S, Dugimont T, Fauquette W, Coll J, Dupouy JP, et al. Steroid hormones modulate $\mathrm{H} 19$ gene expression in both mammary gland and uterus. Oncogene. 1999;18:4460-73.

76. Kino T, Hurt DE, Ichijo T, Nader N, Chrousos GP. Noncoding RNA gas5 is a growth arrest- and starvation-associated repressor of the glucocorticoid receptor. Sci Signal. 2010;3:ra8.

77. Tsai MC, Manor O, Wan Y, Mosammaparast N, Wang JK, Lan F, et al. Long noncoding RNA as modular scaffold of histone modification complexes. Science. 2010;329:689-93.

78. Bhan A, Hussain I, Ansari Kl, Kasiri S, Bashyal A, Mandal SS. Antisense transcript long noncoding RNA (IncRNA) HOTAIR is transcriptionally induced by estradiol. J Mol Biol. 2013;425:3707-22.

79. Zhao JJ, Lin J, Yang H, Kong W, He L, Ma X, et al. MicroRNA-221/222 negatively regulates estrogen receptor alpha and is associated with tamoxifen resistance in breast cancer. J Biol Chem. 2008;283:31079-86.

80. Bergamaschi A, Katzenellenbogen BS. Tamoxifen downregulation of miR451 increases 14-3-3zeta and promotes breast cancer cell survival and endocrine resistance. Oncogene. 2012;31:39-47.

81. Kovalchuk O, Filkowski J, Meservy J, Inntskyy Y, Tryndyak VP, Chekhun VF, et al. Involvement of microRNA-451 in resistance of the MCF-7 breast cancer cells to chemotherapeutic drug doxorubicin. Mol Cancer Ther. 2008;7:2152-9.

82. Bekaii-Saab TS, Perloff MD, Weemhoff JL, Greenblatt DJ, von Moltke LL. Interactions of tamoxifen, N-desmethyltamoxifen and 4-hydroxytamoxifen with P-glycoprotein and CYP3A. Biopharm Drug Dispos. 2004;25:283-9.

83. Teft WA, Mansell SE, Kim RB. Endoxifen, the active metabolite of tamoxifen is a substrate of the efflux transporter P-glycoprotein (multidrug resistance 1). Drug Metab Dispos. 2011;39:558-62.

84. Ward A, Balwierz A, Zhang JD, Kublbeck M, Pawitan Y, Hielscher T, et al. Re-expression of microRNA-375 reverses both tamoxifen resistance and accompanying EMT-like properties in breast cancer. Oncogene. 2013;32:1173-82

85. Ward A, Shukla K, Balwierz A, Soons Z, Konig R, Sahin O, et al. microRNA519 a is a novel oncomir conferring tamoxifen resistance by targeting a network of tumor-suppressor genes in ER+ breast cancer. J Pathol. 2014:233:368-79.

86. Cittelly DM, Das PM, Salvo VA, Fonseca JP, Burow ME, Jones FE. Oncogenic HER2 $\Delta 16$ suppresses miR-15a/16 and deregulates BCL-2 to promote endocrine resistance of breast tumors. Carcinogenesis. 2010;31:2049-57.

87. Cittelly DM, Das PM, Spoelstra NS, Edgerton SM, Richer JK, Thor AD, et al, Downregulation of miR-342 is associated with tamoxifen resistant breast tumors. Mol Cancer. 2010;9:317

88. Manavalan TT, Teng Y, Litchfield LM, Muluhngwi P, Al-Rayyan N, Klinge CM. Reduced expression of miR-200 family members contributes to antiestrogen resistance in LY2 human breast cancer cells. PLoS One. 2013;8:e62334.

89. Jansen MP, Reijm EA, Sieuwerts AM, Ruigrok-Ritstier K, Look MP, RodriguezGonzalez FG, et al. High miR-26a and low CDC2 levels associate with decreased EZH2 expression and with favorable outcome on tamoxifen in metastatic breast cancer. Breast Cancer Res Treat. 2012;133:937-47.

90. Rodriguez-Gonzalez FG, Sieuwerts AM, Smid M, Look MP, Meijer-van Gelder $M E$, de Weerd $V$, et al. MicroRNA-30c expression level is an independent predictor of clinical benefit of endocrine therapy in advanced estrogen receptor positive breast cancer. Breast Cancer Res Treat. 2011;127:43-51.

91. Zhang $Y$, Yang $P$, Sun T, Li D, Xu X, Rui Y, et al. miR-126 and miR-126* repress recruitment of mesenchymal stem cells and inflammatory monocytes to inhibit breast cancer metastasis. Nat Cell Biol. 2013;15:284-94.

92. Meijer D, van Agthoven T, Bosma PT, Nooter K, Dorssers LC. Functional screen for genes responsible for tamoxifen resistance in human breast cancer cells. Mol Cancer Res. 2006:4:379-86.

93. Godinho M, Meijer D, Setyono-Han B, Dorssers LC, van Agthoven T. Characterization of BCAR4, a novel oncogene causing endocrine resistance in human breast cancer cells. J Cell Physiol. 2011;226:1741-9. 
94. Godinho MF, Wulfkuhle JD, Look MP, Sieuwerts AM, Sleijfer S, Foekens JA, et al. BCAR4 induces antioestrogen resistance but sensitises breast cancer to lapatinib. Br J Cancer. 2012;107:947-55.

95. Masri S, Liu Z, Phung S, Wang E, Yuan YC, Chen S. The role of microRNA128a in regulating TGFbeta signaling in letrozole-resistant breast cancer cells. Breast Cancer Res Treat. 2010;124:89-99.

96. Foekens JA, Sieuwerts AM, Smid M, Look MP, de Weerd V, Boersma AW, et al. Four miRNAs associated with aggressiveness of lymph node-negative, estrogen receptor-positive human breast cancer. Proc Natl Acad Sci U S A. 2008;105:13021-6.

97. Taylor MA, Sossey-Alaoui K, Thompson CL, Danielpour D, Schiemann WP. TGF-beta upregulates miR-181a expression to promote breast cancer metastasis. J Clin Invest. 2013:123:150-63.

98. Kazi AA, Sabnis G, Zhou Q, Chumsri S, Schech A, Shah P, et al. HER2 regulated miRNA expression in letrozole resistant breast cancer [abstract]. In Proceedings of the 105th Annual Meeting of the American Association for Cancer Research; 2014 Apr 5-9; San Diego, CA. Philadelphia (PA): AACR; Cancer Res. 2014;74:Abstract nr 1471. doi:10.1158/1538-7445.AM2014-1471

99. Klinge CM. miRNAs and estrogen action. Trends Endocrinol Metab. 2012;23:223-33.

100. Maillot G, Lacroix-Triki M, Pierredon S, Gratadou L, Schmidt S, Benes V, et al. Widespread estrogen-dependent repression of micrornas involved in breast tumor cell growth. Cancer Res. 2009;69:8332-340.

101. Bailey ST, Westerling T, Brown M. Loss of estrogen-regulated microRNA expression increases HER2 signaling and is prognostic of poor outcome in luminal breast cancer. Cancer Res. 2014;75:436-45.

102. Sachdeva M, Wu H, Ru P, Hwang L, Trieu V, Mo YY. MicroRNA-101-mediated Akt activation and estrogen-independent growth. Oncogene. 2011;30:822-31.

103. Shibahara Y, Miki Y, Onodera Y, Hata S, Chan MS, Yiu CC, et al. Aromatase inhibitor treatment of breast cancer cells increases the expression of let-7f, a microRNA targeting CYP19A1. J Pathol. 2012;227:357-66.

104. Deblois G, Giguere V. Ligand-independent coactivation of ERalpha AF-1 by steroid receptor RNA activator (SRA) via MAPK activation. J Steroid Biochem Mol Biol. 2003;85:123-31.

105. Yang L, Lin C, Jin C, Yang JC, Tanasa B, Li W, et al. IncRNA-dependent mechanisms of androgen-receptor-regulated gene activation programs. Nature. 2013;500:598-602.

106. Prensner JR, Sahu A, lyer MK, Malik R, Chandler B, Asangani IA, et al. The InCRNAs PCGEM1 and PRNCR1 are not implicated in castration resistant prostate cancer. Oncotarget. 2014;5:1434-8.

107. Kanasty R, Dorkin JR, Vegas A, Anderson D. Delivery materials for siRNA therapeutics. Nat Mater. 2013;12:967-77.

108. Bader AG. miR-34 - a microRNA replacement therapy is headed to the clinic. Front Genet. 2012;3:120.

109. Beg MS, Borad M, Sachdev J, Hong DS, Smith S, Bader A, et al. Multicenter phase I study of MRX34, a first-in-class microRNA miR-34 mimic liposomal injection [abstract]. In Proceedings of the 105th Annual Meeting of the American Association for Cancer Research; 2014 Apr 5-9; San Diego, CA. Philadelphia (PA): AACR; Cancer Res. 2014;74:Abstract nr CT327. doi:10.1158/1538-7445.AM2014-CT327

110. Sochor M, Basova P, Pesta M, Dusilkova N, Bartos J, Burda P, et al. Oncogenic microRNAs: miR-155, miR-19a, miR-181b, and miR-24 enable monitoring of early breast cancer in serum. BMC Cancer. 2014;14:448.

111. Kodahl AR, Lyng MB, Binder H, Cold S, Gravgaard K, Knoop AS, et al. Novel circulating microRNA signature as a potential non-invasive multi-marker test in ER-positive early-stage breast cancer: a case control study. Mol Oncol. 2014:8:874-83.

112. Wu X, Somlo G, Yu Y, Palomares MR, Li AX, Zhou W, et al. De novo sequencing of circulating miRNAs identifies novel markers predicting clinical outcome of locally advanced breast cancer. J Transl Med. 2012;10:42. 